\title{
MODELO DESCENTRALIZADO DE MEDIAÇÃO PARA RESOLUÇÃO DE CONFLITOS DE REFORMA FUNDIÁRIA URBANA ${ }^{1}$
}

\author{
Rachel Lopes Queiroz Chacur ${ }^{2}$ \\ Celso Maran De Oliveira ${ }^{3}$
}

\begin{abstract}
RESUMO
O presente artigo científico tem o objetivo de tratar da dogmática da exclusividade da Jurisdição para resolução de conflitos de tutelas ambientais, revisitando as bases teóricas e jurisprudenciais, culminando na necessidade de vias alternativas de resolução de conflitos fundiários urbanos, decorrentes da demanda social. É necessária a ruptura do modelo jurisdicional, trazendo um novo paradigma de descentralização e desjudicialização das resoluções de conflitos fundiários urbanos, priorizando a participação democrática dos cidadãos nas tomadas de decisões afeitas ao plano fático do espaço urbano, adequando o caso aos fundamentos das normas constitucionais e infraconstitucionais protetivas dos Direitos Fundamentais do Homem.
\end{abstract}

Palavra-Chave: Direito Urbanístico; Direito Ambiental; Fundiário; Resolução de Conflitos; Mediação.

\section{DECENTRALIZED MODEL OF RESOLUTION OF CONFLICTS OF URBAN FOUNDRY REFORM}

\begin{abstract}
The present scientific article aims to deal with the dogmatics of Jurisdiction exclusivity for the resolution of environmental protection conflicts, revisiting the theoretical and jurisprudential bases, culminating in the need for adequate means and alternative ways of resolving urban land conflicts arising from social demand. It is necessary to break the jurisdictional model, bringing a new paradigm of decentralization and disjudicialization of resolutions of urban land conflicts, prioritizing the democratic participation of citizens in the decisions made to the factual plan of urban space, adjusting the case to the foundations of constitutional norms and Protection of fundamental human rights.
\end{abstract}

Keyword: Urbanistic Law; Environmental Law; Landfill; Conflict resolution; Mediation.

\section{INTRODUÇÃO}

\footnotetext{
${ }^{1}$ O presente artigo científico aborda o desenvolvimento de estudos acerca da "Implantação de um modelo descentralizado de Conciliação e Mediação para a Resolução de conflitos de reforma fundiária urbana no Brasil", sob a perspectiva comparativa de modelos estrangeiros, desenvolvido, em fase inicial, no Projeto de Pesquisa de Doutoramento vinculado ao Programa de Pós-Graduação em Ciências Ambientais, na Universidade Federal de São Carlos - UFSCAR.

${ }^{2}$ Doutoranda em Ciências Ambientais/UFSCar, Mestre em Direito Processual Civil e Advogada.

${ }^{3}$ Doutor e orientador do Programa de Ciências Ambientais/UFSCar.
} 
A doutrina nacional estabelece um entrave teórico e jurisprudencial sobre a necessidade de resolução adequada de resolução de conflitos, em especial, para os conflitos fundiários urbanos, com o objetivo de fomentar o acordo entre as partes para a entrega final da tutela de direito pleiteada, isto posto como litigiosidade contida de vários problemas inerentes à toda sociedade brasileira.

No entanto, mantém-se o debate da obrigatoriedade de judicialização das ações ambientais e urbanísticas, contrariando a imanente eficácia da Lei e própria efetividade da tutela jurisdicional e da tutela de direito ambiental e fundiário (TELLES, 2010).

Tal imperativo de judicialização das lides ambientais e urbanísticas levam à irregularidades e clandestinidade dos imóveis urbanos e rurais, desde a aquisição até a sua transferência definitiva de titularidade de domínio para o legítimo proprietário ou possuidor do mesmo (TIBO, 2011).

De tal sorte, indaga-se a ausência de modelos estruturais descentralizados implantados para resoluções alternativas e adequadas de conflitos ambientais e urbanísticos face ao modelo centralizado judicial dos Poderes do Estado.

Nos últimos anos, houve um avanço nas políticas públicas governamentais destinadas a regularização fundiária urbana, em que pese, com o corolário do advento do Estatuto da Cidade e o Novo Código de Processo Civil.

Com destaque, a exigência de uma nova visão de Gestão e Planejamento da Administração estatal para orientar a regulamentação, as metas e ações, com a participação democrática dos entes envolvidos nos conflitos de interesses, a otimização de instrumentos adequados e resolutivos, bem como para com a implantação de estruturas alternativas de resolução de conflitos fundiários urbanos (OLIVEIRA, 2015).

Contudo, o cerne da discussão está no espaço estrito e reservado da Jurisdição como poder central de resolução de conflitos fundiários urbanos, restando a indagação da possibilidade de descentralização do poder estatal de tomada de decisões governamentais.

Em um primeiro momento, levantam-se o exsurgimento da garantia constitucional do Princípio da Inafastabilidade do Acesso ao Poder Judiciário, com a mitigação do acesso à prestação jurisdicional pela renúncia do cidadão à via jurisdicional, na tentativa de resolução de conflitos fundiários urbanos, de outra forma, senão a administrativa ou outras vias propostas como alternativas para resolução de conflitos de interesses, que envolvem a questão fundiária urbana (PINHO, 2008). 
As reformas legislativas denotam uma ideologia de redução de litigiosidade conflitiva e da massificação de lides temerárias, orientando a delegação do poder judicial, para fomentar outros meios adequados e vias alternativas de resolução de conflitos fundiários urbanos.

Os resultados estatísticos demonstram a inexistência de tratamento do assunto específico de Direito urbanístico e ambiental, com informações não categorizadas, nos bancos de dados do Poder Judiciário brasileiro (LIBÓRIO, et al, 2015).

O contexto demonstra que a Ciência Ambiental, por meio do Direito urbanístico ou Direito ambiental, não se convalidam no âmbito judicial, por meio de cadastros de assuntos e temas nos procedimentos e julgamentos pelo Poder Judiciário, o que evidencia a iminente necessidade de superar os aspectos metodológicos tradicionais dos ramos dos direitos e investigar as demandas ambientais e urbanísticas nos estudos de campo, com a finalidade de adaptação do direito posto com os sistemas administrativos e judiciais existentes, para promover novos métodos alternativos de adequada e fática resolução de conflitos fundiários urbanos.

Tal constatação justifica a necessidade de revisitação da forma de zelar pela prestação administrativa e jurisdicional, das questões concernentes aos conflitos fundiários urbanos, com a adaptação do rito administrativo e judicial, desde a triagem do problema posto, até a resolução dos conflitos e entrega da escrituração definitiva da propriedade urbana.

A metodologia utilizada no desenvolvimento da presente pesquisa é o levantamento e análise do referencial bibliográfico, legislativo, banco de dados oficiais das instituições governamentais e não-governamentais, estruturas organizacionais ou modelos de resolução alternativa de conflitos ambientais fundiários urbanos.

Considerando-se que há uma relação dinâmica e indissociável entre o mundo objetivo e a subjetividade do sujeito, de um grupo e da sociedade, a análise de dados será quanti-qualitativo, pois não é possível traduzi-lo somente em números.

Nas áreas, jurídica e ambiental, são analisadas, de forma lógico-racional as interpretações literais e semânticas da norma processual, sua eficácia, seus efeitos e os seus reflexos na rotina administrativa e forense, bem como no meio social, sempre correlato à temática de resolução de conflitos fundiários urbanos. 


\section{Jurisdição e os Meios Alternativos de Resolução de Conflitos fundiários urbanos.}

A vida em sociedade é regulada por normas jurídicas que compõe o ordenamento jurídico sistêmico e complexo, que disciplinam os atos das pessoas à fim de padronizar as ações aceitas e as ações reprovadas pela sociedade. Tais regulamentos são elaborados pelo Estado de Direito, tendo como papel preponderante instituir meios de imposição coativa do comando expresso da norma, para reduzir o número de litigiosidade contida.

É por meio da função legislativa que o Estado estabelece a ordem na sociedade, fixando preventivamente as normas jurídicas que deverão ser respeitadas pelos homens, na solução de seus conflitos, perante a sociedade.

O ordenamento jurídico brasileiro, composto por todas as normas jurídicas, define aos cidadãos seus direitos e deveres, sendo que estes devem respeitar, em proveito do bem comum e da pacificação social. O dever de respeitar as normas impostas pelo Estado se baseia no fato de que os cidadãos escolhem seus mandatários, que os representam e legislam em seu nome, de acordo com o que a sociedade anseia, na contemporaneidade de seu tempo.

Para àqueles que não cumprem o regramento, cabe ao Estado adotar medidas de coação, sempre visando, além da punição pelo ato reprovado pela sociedade, a reinserção do indivíduo à sociedade. Nesses casos é função do Estado punir o ato de descumprimento das normas jurídicas, mantendo a segurança jurídica das relações sociais.

Ocorre que, o conceito de Estado teve transformações durante os diferentes períodos históricos. Nos primórdios da civilização este era fraco e limitava-se a meramente definir os Direitos. Os conflitos existentes eram resolvidos mediante a imposição da vontade do mais forte sobre o mais fraco, ação classificada pela doutrina como autotutela. Esse método usado para solucionar os conflitos era incipiente e incapaz de gerar a paz social desejada, não garantindo a Justiça (ALVIM, 2015).

No século XVIII surgiu o ente estatal denominado Poder Judiciário, centralizado na figura do Juiz, para tomadas de decisões norteadas por um arcabouço legalista e ponderado pela argumentação teórico e científica, com o cunho de dar equilíbrio e isenção nas resoluções das demandas. Em uma breve análise de corte temporal, a história do Direito demonstra a obrigatoriedade da Jurisdição, até o final do século XX (PAIM, 2011).

O Direito contemporâneo retoma o debate do dogma da centralização da Jurisdição, decorrente das demandas judiciais, levantando as possibilidades, no plano fático e jurídico, de 
ruptura de paradigmas de exclusividade do poder judicial para um modelo alternativo de conflitos fundiários urbanos.

A autoridade estatal ou soberania, tradicionalmente tida como una, indivisível, inalienável e imprescritível, é o principal elemento estruturante que caracteriza a centralização do Poder do Estado. Com a instituição do poder soberano do Estado surgem os diferentes tipos de governo e os súditos se submetem ao domínio do soberano, transferindo-lhe sua liberdade e obedecendo aos preceitos deste; a finalidade da obrigação é a proteção (FERREIRA FILHO, 2015).

O Estado detém uma organização política que regula e monopoliza o uso da força, regulamentando as regras de uma sociedade politicamente organizada, por meio do Direito. Atrelada à força, portanto, está a ordem, que é dada principalmente para fins de fazer cumprir direitos e possui dispositivos sancionatórios para fins de obrigar o seu cumprimento, por conta da função jurisdicional do Estado, o qual possui legitimidade e autoridade central (NADER, 2017).

As transformações históricas mantém o monopólio pelo Estado, como cerne da manutenção da Soberania do Estado, em que a figura do Juiz dotada de neutralidade e imparcialidade justifica a permanência de um dogma jurídico de exclusividade de poder para aplicação da Lei e resolução de conflitos de interesses, com o pretenso objetivo-fim de pacificação social (MORAIS; MAZZA, 2012).

Da mesma forma, a doutrina correlata das Ciências Ambientais e jurídicas, aproveita a definição das características da Jurisdição, por conseguinte, com: o caráter substitutivo, sendo que o Estado age de modo secundário, exercendo um ato em substituição às atividades daqueles que estão envolvidos no conflito; em que o papel de atividade estatal provocada de acesso aos órgãos da jurisdição fica entregue ao poder dispositivo do interessado, sendo aqueles inertes; por fim, a característica da definitividade, apenas coloca a solução de conflitos interindividuais, seja no âmbito extrajudicial ou judicial, por meio da decisão ou homologação judicial, excepcionalmente, com a reapreciação do julgado, para findar na resolução do conflito de interesse (CINTRA, 2011).

No entanto, de forma global e complexa, o entendimento que melhor caracteriza a Jurisdição como atividade secundária, instrumental, declarativa, desinteressada e provocada. Secundária porque o Estado realiza uma atividade que deveria ter sido primariamente exercida, de maneira pacífica, pelos próprios sujeitos da relação jurídica; instrumental, visto que considera como objetivo principal da jurisdição dar atuação prática às 
regras do direito; declarativa, pois exercita a lei nascida anteriormente ao pedido da tutela jurídica estatal, feito pela parte no processo; desinteressada no sentido de que o juiz se mantém distante dos interessados, sendo sua atividade subordinada exclusivamente à lei; por fim, provocada, porque a Jurisdição espera ser provocada pela parte insatisfeita (THEODORO JUNIOR, 1995, p. 537).

Logo, modernamente, conceitua a Jurisdição como um poder de formular e fazer atuar praticamente a regra jurídica concreta que disciplina determinada situação jurídica.

Considerando os pontos comuns conclui-se que a Jurisdição é uma atividade estatal provocada, tendo como objeto de litígio disponível e com restrições indisponível, podendo as partes procurarem outras soluções e caminhos para resolução da lide, que não um longo processo.

A solução pode se dar por meios de auto-composição de litígios (Mediação e Conciliação) ou por decisão de pessoas estranhas ao Poder Judiciário, na figura dos árbitros (OLIVEIRA, ZANQUIM JUNIOR; ESPINDOLA, 2016).

Importante ressaltar que, não são todos os conflitos de interesse que se compõem por meio exclusivo da Jurisdição, mas apenas aqueles que configuram a lide, ou seja, um conflito de interesses qualificados por uma pretensão resistida, o que justifica a possibilidade plausível de descentralização da resolução de conflitos de interesses urbanos fundiários e estrito julgamento ou homologação pelo Poder Judiciário (TONIN, 2016).

A resistência dos conflitos de interesses fundiários urbanos que versam sobre direitos indisponíveis e disponíveis, o que demonstra uma forma diferenciada de conflituosidade, em que há necessidade de vários atores participarem da discussão acerca do direito, distanciandose do modelo bilateral de resistência qualificada de conflitos de interesses e vislumbrando uma nova análise das relações conflitivas circulares, interacional, com inferências de setores diversos da sociedade e reflexos diretos e indiretos nos eixos normativos e planos fáticos dos conflitos existentes, no âmbito fundiário urbano (CHACUR; OLIVEIRA, 2015).

O modelo centralizado estatal da Jurisdição não comporta a adequada resposta da prestação jurisdicional aos cidadãos, levando os pesquisadores das áreas interdisciplinares formular propositivas contrárias ao modelo posto, analisando o fato conflitivo, com uma visão deformalizante processual, com a reestruturação administrativa do poder administrativo e judicial, para resolução de conflitos fundiários urbanos (ZANFERDINI, 2015). 
A crise estatal, jurisdicional, econômica e social é latente, cabendo à Ciência contribuir para com um novo paradigma de resolução de conflitos fundiários urbanos (GRINOVER; CINTRA, 2006).

\section{Meios Adequados e vias alternativas de Resolução de Conflitos fundiários urbanos.}

O contexto do sistema econômico e global do desenvolvimento do Estado evidencia a condição de desigualdades dos indivíduos em sociedade, tendo como resultado o distrato e o conflito social, pelo espaço urbano.

A realidade social é fator determinante para mensurar o grau de litigiosidade de uma determinada sociedade.

Nesta tentativa equalizadora dos eixos do sistema econômico, social e jurídico, ficam os atores sociais, em constante, reivindicações de seus direitos, por meio do acesso ao Poder Judiciário, em um jogo de acomodação e desacomodação interna e conflitiva das relações sociais (LUHMANN, et all. 2016).

Aquela visão positiva e isolada do surgimento do Estado, baseada no modelo contratualista, o qual prevê a necessidade da criação de um pacto social entre os indivíduos e um representante dotado de poder, capaz de defendê-los e protegê-los (HOBBES, 1651) ou a visão do Estado da Natureza ao Estado das coisas para analisar tão somente a origem do direito e sua natureza conflitiva (JONH LOCKE, 1664) e seja em qual forma a concepção da busca pelo direito, o alcance da busca pela Felicidade (ROSSEAU, 1780), isoladamente, em que pese o ganho científico das teorias clássicas no desenvolvimento da Ciência, hoje, não respondem aos conclâmos da resolução desta litigiosidade (SOUSA, 1998).

A Filosofia do Direito moderno enfatiza a finalidade da Teoria do Direito Fraterno embasada nos ideais da Liberdade e Igualdade, advinda do recorte temporal e histórico da Revolução Francesa. Essa ideia de fraternidade está diretamente ligada à vida em sociedade, à cidadania ativa entre os homens e a prevalência dos Direitos Humanos, dando tratamento igualitário e liberdade ao Homem, com a finalidade de se viver em harmonia fraterna (ADORNO, 2017). 
Esse marco epistemológico resgata a preocupação dos juristas, com a análise dos motivos que geram a violência e conflitualidade social, saindo da competência exclusiva do Estado para resolução de litígios e permitindo a criação de políticas públicas gestoras de Mediação de conflitos, como suporte de implementação de mecanismos para trazer benefícios à solução pacífica e harmônica das lides, em especial, nas questões conflituosas na área fundiária urbana (PINHO, 2013).

Neste contexto, que o Direito Fraterno adquire uma dimensão cosmopolita, onde a minimização da violência leva à ideia de Jurisdição mínima, dando vazão a descentralização do poder para resolução dos conflitos fundiário urbanos.

A proposta fraterna é o embasamento teórico da Mediação e das demais formas alternativas de resolução de conflitos sociais. A Mediação, portanto, é considerada uma das melhores formas da concretização do ideal fraterno, pois consiste na construção de uma decisão pelos conflitantes e não sua imposição. Além disso, possui caráter humano e cidadão, pois preserva a igualdade entre as partes, bem como a liberdade. A participação total das partes, inclusive na decisão final, faz com que a Mediação se sobreponha às demais formas extrajudiciais de resolução de conflitos. Tal procedimento, além da celeridade e eficiência, traz mais satisfação e sucesso, visto que atua na verdadeira causa do problema e proporciona mudanças sociais na vida dos demandantes e da sociedade como um todo (GHISLENE; SPENGLER, 2011).

Em tempos de globalização, a Mediação constitui tendência liberal que mantém estreita relação com a retirada cada vez maior do Estado dos assuntos de interesse dos particulares, devido às fórmulas tradicionais de resolução das controvérsias não satisfazerem mais os usuários do sistema, cada vez mais envolvidos em conflitos de distintas naturezas e formas, dada a complexidade das numerosas interrelações existentes nos tempos atuais. Lembrando que, toda e qualquer relação conflitiva contém, implicitamente, um contrato psicológico, baseado nas expectativas tácitas, conscientes e inconscientes que cada pessoa tem a respeito das outras nele envolvidas, as quais levam a alteração de um sistema, em decorrência de uma necessidade de mudança de paradigma social (SAMPAIO; BRAGA NETO, 2007).

A origem terminológica de Mediação deriva do latim de mediare significa "dividir ao meio", enquanto alternativa fraterna de tratamento dos conflitos pressupõe uma convivência baseada na convivência harmoniosa entre cidadãos fraternos, Direitos humanos, Jurisdição mínima, consenso, diálogo e direito compartilhado. É um modelo realmente 
democrático e não violento que aposta no bem comum, abandonando o conceito litigioso adjetivo de vencedor e vencido, abrindo novos modelos e espaços de debates para a resolução de conflitos de interesses. Não se trata de negação da figura do Estado, mesmo porquê não exclui a judicialização dos conflitos de interesses, porém, favorece um novo tratamento de resolução de conflitos, pelas vias extrajudiciais, os quais trazem resultados mais ajustados aos interessados, ou seja, remonta a característica secundária da Jurisdição (GORETTI, 2017).

Deste modo, pretende-se comprovar os benefícios trazidos pelo Direito Fraterno, já que o Poder Judiciário apenas resolve a lide, mas não consegue solucionar o real problema social e evitar novas contendas. Também colaborar com as discussões profissionais e acadêmicas sobre o tema, apostando em uma sociedade fraterna e solidária (GHISLENE; SPENGLER, 2011).

É importante destacar que, inicialmente, os métodos alternativos não foram criados para substituir o método tradicional de utilização do sistema judicial, mas para propiciar outra opção de resolução de seus conflitos para as pessoas físicas ou jurídicas que buscam soluções diferenciadas, específicas e, talvez, especializadas para suas distintas interrelações. Caminho, opção ou alternativa mais pacífica que prima por meios menos formais e, acima de tudo, prescinde da negociação para que todo seu processo seja impulsionado. Tendo como característica principal, o emprego da negociação como instrumento primeiro e natural para solucionar os conflitos, ao qual muitas vezes recorrem seus agentes, mesmo de modo inconsciente, quando existe algo incômodo na interrelação existente, seja ela de ordem afetiva, profissional ou empresarial (SAMPAIO; BRAGA NETO, 2007).

As pesquisas identificaram métodos estabelecidos inicialmente pelo Projeto de Negociação da Harvard Law School identificaram dois perfis básicos de negociador: um denominado afável — sempre faz concessões e troca de posições constantemente, pois procura preservar o relacionamento, uma vez que identifica a outra parte como parceira; e outro chamado rígido - pois nunca muda de posição, tenta vencer todas as disputas, pensa apenas em si mesmo e vê a outra parte como um oponente a ser combatido. Enquanto que, Roger Fisher, Bruce Paton e Willian Ury, lançaram as bases de uma negociação estruturada, denominada negociação por princípios, ou, como muitos a chamam de negociação cooperativa. Eles sustentam que o objetivo da negociação não é atingir a meta determinada de uma ou de outra parte (posição), porém, atender aos interesses comuns e opostos das partes, subjacentes e ocultos pelas posições. Destacam a separação das pessoas e o problema, a criação de opções e valores e os critérios objetivos. De forma geral, pode-se falar de um 
modelo tradicional, proveniente do campo empresarial, centrado na satisfação individual das partes e que visa à obtenção de um acordo. Este é o modelo da escola de Havard, que separa as pessoas do problema, enfoca os interesses e não as posições, cria opções para benefício mútuo e insiste nos critérios objetivos (LIMA, 2017).

Tem-se, também, o modelo transformativo, desenvolvido por Bush e Folger, que vê como êxito a transformação das pessoas no sentido do crescimento, da revalorização pessoal e do reconhecimento da legitimidade do outro. O acordo é encarado como uma possibilidade e não como uma finalidade (TARTUCE, 2016).

Outro modelo de mediação é o circular-narrativo desenvolvido por Sara Cobb e Marinés Suares, em que a fundamentação se faz na comunicação e na causalidade circular, cuida-se dos vínculos e fomenta-se a reflexão, possibilitando a transformação de uma história conflitiva em uma história colaborativa. Muitos são os modelos e métodos que podem ser empregados nas mais diversas áreas sociais (GABBAY, 2011).

São inúmeras as matérias pertinentes afeitas à implementação do instituto da Mediação judicial e extrajudicial para resolução alternativa de conflitos individuais, coletivos ou difusos, exemplificadamente, para as disputas em família, nas empresas, nas relações comerciais e de consumo, na gestão educacional, em particular, naquilo que interessa ao tema em questão no âmbito do Direito Ambiental e Urbanístico (PINHO, 2013).

O Direito Ambiental é caracterizado pela indeterminação dos sujeitos, indivisibilidade de seu objeto e difusão de seus interesses, existência de vínculos fáticos entre os titulares, transição e mutação no tempo e no espaço e, por último, intensa litigiosidade interna (MACHADO, 2016).

Um estudo de caso emblemático é a proteção de determinado recurso hídrico, o que pode envolver direitos indisponíveis e disponíveis, evidenciando o antagonismo de objetivos da própria resolução de conflitos, porém, possíveis de serem resolvidos pelos pares e agentes interessados. Por conseguinte, afeta a forma diferenciada de tratamento da tutela de direito e solução de conflitos de interesses, no bojo de uma mesma relação de interesse jurídico, cultura, sócio e econômico (OLIVEIRA, 2015).

O objeto do Direito envolvido nas relações conflitivas ambientais e urbanísticas, também devem ser tratadas, de forma prioritária e criativa, por corresponder à condições mínimas de sobrevivência e subsistência do Homem, nos espaços comunitários, para tanto justificam-se a continuidade dos estudos sobre o tema para buscar instrumentos aptos de resolução de conflitos, em tempo hábil e à contento para a sociedade. 
O instituto da Mediação de conflitos nas questões ambientais e urbanísticas tem-se mostrado um sistema adequado parcial e pouco utilizado, com experiências isoladas, pois possibilita, incialmente, o diálogo entre todos os envolvidos, proporciona a conservação e melhoria da interrelação existente e, em um segundo momento, permite a prevenção de futuras disputas, ao mesmo tempo em que leva à conscientização ecológica daqueles atores, pelos compromissos assumidos nos Termos de Conduta firmados entre os mediados (OLIVEIRA; ESPÍNDOLA; ZANQUIM, 2016).

Diante do contexto contemporâneo, verificam-se aplicações isoladas de Mediação para Resolução de Conflitos fundiários urbanos, como é a hipótese classificatória e empírica da Mediação comunitária, a qual promove a criação de espaços de diálogo, com a escuta respeitosa e a participação ativa, em um trabalho cooperativo, dinâmico e pacífico de seus respectivos atores sociais sobre seus lugares e espaços sociais. Ela permite, também, estabelecer canais facilitadores para a articulação política, institucional e social, convidando a todos para uma reflexão responsável sobre a diversidade das temáticas da realidade atual e constituindo um desafio para o mediador comunitário em preservar uma sociedade pluralista, equitativa e integradora (SAMPAIO; BRAGA NETO, 2007).

O insurgimento do debate do tema trouxe a promoção do Terceiro setor, integrado por organizações sem fins lucrativos, o qual capta cidadãos voluntários, com o ânimo de utilização de meios facilitadores de Mediação de Conflitos (CHACUR; OLIVEIRA, 2015).

No Brasil, permanece a cultura da judicialização da litigiosidade contida ambiental, com procedimentos exacerbados e um distanciamento do direito posto ao sistema implementado para gestão de conflitos ambientais fundiários urbanos, não tendo um modelo e estrutura adequada e especializada para atender a demanda de ações ambientais (FARIA; MATOSINHOS, 2016).

De um lado têm-se a demanda e a Lei, por outro não há sistema válido, norma eficaz e modelo apto e uniforme, com estrutura administrativa, com o direcionamento de ações resolutivas de conflitos e o cumprimento das políticas públicas, atinentes as especificidades da resolução de irregularidades da ocupação dos espaços urbanos.

É urgente a formatação de um modelo uniforme de resolução de conflitos fundiários urbanos, por meio de uma análise comparativa do sistema legal e da estrutura funcional e organizacional dos órgãos administrativos e judiciais, levando-se em consideração a primazia das opções não-adversariais e espaços comuns para resolução alternativas de conflitos fundiários urbanos nas cidades brasileiras. 


\section{CONCLUSÃO}

A observância das previsões normativas constitucionais garantidoras de um meio ambiental equilibrado e sustentável não corresponde aos reais conclâmos das demandas sociais, com a constatação da existência da condição de irregularidade e clandestinidade nas ocupações dos espaços urbanos.

A conjuntura social revela a necessidade do fomento de políticas públicas, com o fim de legitimação da posse precária, como fator de inclusão da própria identidade dos cidadãos brasileiros pertencentes ao seu espaço urbano.

No entanto, o desenfreamento de alocação de espaços urbanos levam a precariedade e a irregularidade da posse, em desrespeito as exigências de regularização fundiária urbana contidas nas legislações extravangantes e na Constituição Federal, recaindo em uma litigiosidade contida, com a hiperjudicialização, com ritos e procedimentos exacerbados e sem mecanismos aptos e estrutura para resolução dos conflitos fundiários urbanos.

A tendência dogmática e filosófica do Direito Fraterno justifica a utilização do instituto da Mediação, no âmbito extrajudicial e judicial, e demonstra um novo caminho metodológico de debates científicos, porém, a proposta apresenta a sugestão da implantação de um modelo descentralizado de resolução de conflitos fundiários urbanos.

Desta feita, é pertinente o aprofundamento da nova temática no âmbito das disputas fundiárias, para promoção de políticas públicas voltadas ao uso, gozo e fruição plena dos direitos inerentes a propriedade pelos cidadãos, contemplando-os o Direito Fundamental à Moradia, como bem Maior da vida digna.

Cabe às Ciências Ambientais, em um debate inter e multidisciplinar, com recortes transversais e inferências locais, promover a difusão científica de propostas de descentralização e desjudicialização de resolução de conflitos fundiários urbanos, pela importância e magnitude dos problemas advindos da sociedade brasileira.

\section{REFERÊNCIAS BIBLIOGRÁFICAS}


ADORNO, Sérgio. Conflitualidade e violência: reflexões sobre a anomia na contemporaneidade. Tempo social, São Paulo, v. 10, n. 1, p. 19-47, maio 1998 . Disponível em<http://www.scielo.br/scielo.php?script=sci_arttext\&pid=S010320701998000100003\&lng =pt\&nrm=iso>. Acesso em 12 de maio 2017. http://dx.doi.org/10.1590/S010320701998000100003.

ALVIM, José Eduardo. Carreira. Teoria Geral do Processo. Editora GEN, Rio de Janeiro, 2015 .

CINTRA, Antonio Carlos de Araújo; GRINOVER, Ada Pellegrini; DINAMARCO, Cândido Rangel. Teoria Geral do Processo. São Paulo: Malheiros Editora, 2011.

CHACUR, Rachel Lopes Queiroz; OLIVEIRA, Celso Maran de. Novo Código de Processo Civil versus a Judicialização para a Implementação das Políticas Públicas do Meio Ambiente. In: I CONGRESSO NOVOS DIREITOS. São Carlos. Anais. São Carlos, 2015. FARIA, Edimur Ferreira; MATOSINHOS, Paula. Regularização Fundiária por Interesse Social na Legislação 11.977 de 07 de Julho de 2009: o excesso procedimental na exigência da legitimação da posse. Revista de Direito Urbanístico, Cidade e Alteridade. v. 2, n. 1, p. 254-273, Jan/Jun. 2016. Disponível em < file://C:/Users/Administrador/Downloads/517-1034-2-PB\%20(1).pdf>. Acesso em 12 de maio de 2017.

FERREIRA FILHO, Manoel Gonçalves. Curso de Direito Constitucional. Saraiva, São Paulo, 2015.GABBAY, Daniela Monteiro. Mediação e judiciário: condições necessárias para a institucionalização dos meios autocompositivos de solução de conflitos. Tese da Universidade de São Paulo. São Paulo, 2011.

GHISLENI, Ana Carolina; SPENGLER, Fabiana Marion. Mediação de conflitos a partir do direito fraterno [recurso eletrônico], Santa Cruz do Sul: EDUNISC, 2011.

GORETTI, Ricardo. Mediação e Acesso à Justiça. JusPodivum, Salvador, 2017.

GRINOVER, Ada Pelegrini; CINTRA, Antônio Carlos de Araújo. Teoria Geral do Processo. São Paulo: Malheiros, 2006.

GUIMARÃES, Irene Maestro S. Santos (Org.). Direito Urbanístico em juízo: Estudo de Acórdãos do Tribunal de Justiça do Estado de São Paulo. São Paulo: IBDU, 2016. HOBBES, Thomas. Leviatã. Tradução de João Paulo Monteiro e Maria Beatriz Nezza da Silva; p.111; Abril S.A Cultural e Industrial, São Paulo; 1974.

KUNZLER, Caroline. A Teoria dos Sistemas de Niklas Luhmann. Estudos de Sociologia. Consultado em 12 de julho de 2016. 
LIMA, Fernanda Maria Dias de Araújo; ALMEIDA, Maurício Vicente Silva. A mediação harvadiana e a mediação transformativa. Revista Âmbito Jurídico. Rio Grande do Sul, 2017. Disponível:http://www.ambitojuridico.com.br/site/index.php?artigo_id=8622\&n_link=revista artigos leitura\# ftnref1.

LIBORIO, Daniela Campos; FROTA, Henrique Botelho; CARDOSO, Patricia de Menezes. Direito Urbanístico em juízo. IBDU. Editora Fórum, São Paulo, 2016.

LOCKE, John. Segundo Tratado do Governo Civil. Editora Vozes, Rio de Janeiro, 2006. MACHADO, Paulo Afonso Leme. Direito Ambiental brasileiro. Revista dos Tribunais, São Paulo, 2016.

MILARÉ, Edis. Direito do Ambiente - A Gestão Ambiental em foco. Revista dos Tribunais, São Paulo, 2013.

MORAIS, José Luiz Bolzan. MAZZA, William e Parente. Estado Contemporâneo Direitos Humanos, Democracia, Jurisdição e Decisão. Curitiba: Juruá. 2012.NADER, Paulo. Filosofia do Direito. Forense, São Paulo, 2017.

OLIVEIRA, Celso Maran de. Novos Direitos - Cidades em crise? São Carlos: RiMa, 2015. OLIVEIRA, Celso Maran de; ZANQUIM JUNIOR, José Wamberto; ESPINDOLA, Isabela Battistello. The Arbitral Tribunal as an alternative legal instrument for solving water conflicts in Brazil. Ambient. soc., São Paulo, v. 19, n. 1, p. 145-162, Mar. 2016.

Disponível: $<$ http://www.scielo.br/scielo. php?script=sci_arttext\&pid=S1414753X2016000100009\&lng=en\&nrm=iso>. Acesso em 12 de Maio 2017. http://dx.doi.org/10.1590/1809-4422asoc150150r1v1912016.

PAIM, Gustavo Bohrer. Breves Notas sobre o Direito Processo Civil Romano. Revista Eletrônica: Temas Atuais de Processo Civil, v. 1, nº 3, Setembro de 2011. PINHO, Humberto Dalla Bernardino de. Mediação judicial e garantias constitucionais. $1^{\text {a }}$ Edição, Niterói, 2015.

SPENGLER, Fabiana Marion; PINHO, Humberto Dalla Bernardina. Acesso à justiça, jurisdição (in) eficaz e mediação: a delimitação e a busca de outras estratégias na resolução de conflitos [recurso eletrônico] - Curitiba: Multideia, 2013.

Coordenador: Humberto Dalla Bernardino de Pinho

Colaboradores: Ana Carolina Weber, Diogo Assumpção Rezende de Almeida, Fernanda Medina Pantoja, Flávia Pereira Hill, Humberto Dalla Bernardino de Pinho, Maurício Vasconcelos Galvão Filho e Vítor Carvalho Lopes. Teoria Geral da Mediação. Rio de Janeiro: Lumen Juris, 2008. 
ROUSSEAU, Jean Jacques. Contrato Social. L\&PM Editores. Livro digital. São Paulo, 2017.

SAMPAIO, Lia Regina Castaldi; BRAGA NETO, Adolfo. O que é Mediação de Conflitos. São Paulo: Brasiliense, 2007.

SOUSA, José Pedro Galvão de; Clóvis Lema Garcia, José Fraga Teixeira de Carvalho.

Dicionário de Política. São Paulo: T. A. Queiroz, 1998.

TARTUCE, Fernanda. Mediação para Resolução de Conflitos. São Paulo: Método, 2016.

THEODORO JUNIOR, Humberto. Curso de Direito Processual Civil. São Paulo: Revista dos Tribunais, 1995.

TELLES, Vera da Silva. A cidade nas fronteiras do legal e ilegal. Arguvmentvm. Editora Belo Horizonte, 2010.

TIBO, Geruza Lustosa de Andrade. A superação da ilegalidade urbana: o que é legal no espaço urbano? 2011. 236 f. Dissertação (Mestrado em Arquitetura e Urbanismo) - Escola de Arquitetura e Urbanismo, Universidade Federal de Minas Gerais, Belo Horizonte, 2011. TONIN, Mauricio. Solução de Controvérsias e Poder Público: Negociação e Arbitragem. Tese de Doutorado na Universidade de São Paulo. São Paulo, 2016.

ZANFERDINI, Flávia de Almeida Montingelli. Desjudicializar conflitos: uma necessária releitura do acesso à justiça. Revista Novos Estudos Jurídicos, Itajaí, SC, v. 17, n. 2, p. 237 253, mai.-ago. 2012. Disponível em < file:///C:/Users/Administrador/Downloads/3970-98941-PB.pdf>. Acesso em 20 mar. 2016. 